\title{
Oxygen free graphene/TiO2 nanocomposite synthesis technique for dye-sensitized solar cells photo-anode
}

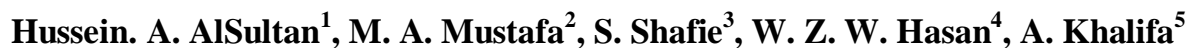 \\ ${ }^{1,2,3,4}$ Department of Electrical and Electronic Engineering, Faculty of Engineering, University Putra Malaysia, Malaysia \\ ${ }^{2,3,4,5}$ Institute of Advanced Technology, University Putra Malaysia, Malaysia
}

\begin{tabular}{l}
\hline Article Info \\
\hline Article history: \\
Received Jun 15, 2019 \\
Revised Aug 16, 2019 \\
Accepted Aug 30, 2019 \\
\hline
\end{tabular}

Keywords:

DSSCs

GNP

Low-cost method

Nanocomposite

$\mathrm{TiO} 2$

\begin{abstract}
This article presents the techniques for the synthesis of oxygen-free graphene for doped in titanium dioxide $\mathrm{TiO} 2$. This work hypothesised the introduction of a new method for incorporating graphene nanoplatelets GNP in Anatase $\mathrm{TiO} 2$ using adhesive nanocomposite material, which has been done to enhance the conductivity of the nanocomposite. This work also argues with lamina problems in Graphene oxide, which reduce electron mobility and cause the electron pathways to be rerouted. The characteristics of the nanocomposite measure the colour difference, the photocurrent-voltage measurement (I-V measurement), Raman Spectroscopy, and Energy Dispersive Spectroscopy EDS. Simple visual observation results for various thin films show a colour shade difference due to the better dispersion of the nanocomposites. The uniform colour change with different weight ratios can also show the distribution of graphene sheets. Similarly, similar ratios to photocurrent-voltage readings were obtained by the different nanocomposite weights in I-V measurement. The Raman spectroscopy also recognises the existence of well-composed 2D energy band GNP sheets cooperated inside the TiO2. Finally, the work concludes with the reduction of the oxygen in weight ratios atomic, which lead to a better atomic level and the optimal weight ratio of GNP sheets to Titanium to increase the free mobility of electrons.
\end{abstract}

Copyright $\odot 2020$ Institute of Advanced Engineering and Science. All rights reserved.

\section{Corresponding Author:}

Hussein. A. AlSultan,

Department of Electrical and Computer Engineering,

University Putra Malaysia,

43400 UPM Serdang, Selangor, Malaysia.

Email: mrkaspersos@gmail.com

\section{INTRODUCTION}

\subsection{Background of the Study}

In his 2003 speech at Rice University, Nobel prize winner Richard Smalley listed environment and energy as one of the ten issues facing humanity [1]. He stressed the high demand for sustainable energy sources. Today, the human population growth and the ongoing rapid increase in demand for energy have resulted in an environmental crisis because our energy demands are dependent on fossil fuels and generate greenhouse gas. Renewable sources such as biomass, hydropower, geothermal, tidal, ocean waves and wind energy have nevertheless received much attention. Furthermore, a significant focus was placed on solar energy due its abundance. However, the high cost of manufacturing and low market share for the $2^{\text {nd }}$ generation silicon based solar cells has slowed the investment for such a formatable energy source, Furthermore, after O'Regan and Gratzel's pioneering work in 1991 [2] Who published the paper introducing low-cost, high-efficiency solar cell development (DSC's or DSSCs) devices I which started the $3^{\text {rd }}$ generation solar cells, in comparison with $2^{\text {nd }}$ photovoltaic silicon devices, these devices use low cost and possible nonenvironmentally hazardous materials and processes. 


\subsection{DSSCs}

The DSSC is designed of three main parts (photoelectrode, electrolyte and counter electrode) and a sandwich of two conducting glass substrates. [3]. The use of semiconduction such as Tin oxide (SnO2), titanium dioxide $(\mathrm{TiO} 2)$ or zinc oxide $(\mathrm{ZnO})$, which acts as scaffolding material in dye molecules, also provides a transmission medium for electron charge when electrons reach the conduction band. [4]. However, due to its superior properties, such as low toxicity, high chemical stability and mesoporous microstructure, $\mathrm{TiO} 2$ is considered the most useful and practical semiconductor. Moreover, anatase (tetragonal) is the most used from three primary crystalline forms of titanium because of its high electron mobility [5, 6]. However, TiO2 only absorbs photons in the ultraviolet light region and has a high speed of recombination problem with electron-hole recombination. [7]. Illuminating light to the cell can stimulate the electrons in the dyes and promotes electrons from Highest Occupied Molecular Orbital (HOMO) to the Lowest Unoccupied Molecular Orbital (LUMO), which also improves the conduction band (CB). [4, 8].

A significant influence affecting device performance is a modification of the DSSCs photoanode by doping, morphology and by changing the thickness [5]. A variety of materials based on noble metal elements have been evaluated to enhance the performance of TiO2. The superior candidates are Gold based (Au-NPs) [9], since gold acts as a high-efficiency dye sensitiser for typical plasma-induced enhancement of light absorption giving rise to a high photocurrent. A gold-nanostar morphology is employed (Au- nanostars) to enhance photovoltaic performance light absorption, [10], that improves performance in DSSCs due to its anisotropic properties. Another study realises Silver Nobel Metals (Ag-NPs) [11] formed as nano-composite photoanodes to enhance light absorption attributed to Surface Plasmon Resonance (SPR). Furthermore, that study of Ag-NPs deposited on titanium nanotubes TNT arrays demonstrates a higher conversion rate without Ag-NPs. However, most studies review rare earth element dopant materials, which are prohibitive for mass-production due to processing cost.

In 2004 two scientists Andre Geim and Konstantin Novoselov discovered Graphene [12]. A capable material that has exceptional superconducting characteristics in one atom. Those capabilities inspired many potential new ideas for research that focus on device efficiency. Partially because of the oxygen reaction medium, it is, of course, an oxidising agent, notably since the efficiency of Graphene in photocatalyst activity can be improved with Anatase rather than Rutile [13]. Moreover, comprehensive research has been explored as a photoanode enhancer concerning graphene, graphene oxide and many other types of carbon. Carbon as non-metallic anions was mostly incorporated into the DSSCs, the redshift of carbon-doped TiO2 as inspected in the UV / Vis spectrum, and the XPS measurement indicates a reduction in the band gap resulting in higher conductivity, as can be observed on Jsc, and the intensity of electron transport as shown by improved lifespan [4]. Wang et al. performed a three-step technique of forming a $\mathrm{TiO} 2$ porous photoelectrode model using graphene oxide. Due to the sheet formation of the graphene into the titanium framework, the TiO2-GO has improved the conversion efficiency and formed a porous framework. [14], Modified hummer method has been implemented in another research by Wang and Cho [15], to decrease GO to rGO. The situation of the research is to design three layers of $\mathrm{TiO} 2-\mathrm{rGO}$ film which include several proportions of the graphene doped in the $\mathrm{TiO} 2$ for the DSSC photoelectrode as GR or rGO could be acquired by using an autoclave as a result of the decrease of GO. The UV-vis absorption spectrum results in an excessively elevated or low graphene content which was not desirable to adsorb dye. An adequate material of decreased graphene can make TiO2 nanoparticles more evenly distributed. A Peiris et al [16]. stacked rGO-TiO2 study initialized by the method of electrophoretic deposition (EPD) to position stacked film alternativerGO-TiO2 photoanode in a set electrode layer thickness. Due to better current short circuit with the Graphene, which acts as a bridge to the FTO glass substratum, the overall interlayer incorporation $\mathrm{TiO} 2$ has achieved $40 \%$ higher efficiency than the standard cell meeting the same conditions. In addition, a greater amount of stacks have resulted in a reduced present short circuit owing to serious interface changes that generate more routes to unwanted instructions. In a research on titanium (IV) isopropoxide (TTIP) with distinct wt percentage ratios of graphene oxide reduced(rGO), one step sol precipitation peptization method was implemented while using two kinds of dye, well-known N-719 (synthetic dye) and natural green chlorophyll (organic dye). The resulting effectiveness is 3.95 percent for the TrGO-2 $0.03 \mathrm{~g}$ wt ratio and 0.67 percent for the natural green day [17].

Many studies on bandgap reduction by cooperating $\mathrm{TiO}_{2}$ with graphene oxide $\mathrm{GO}$ or reduced graphene oxide rGO composite has shown that the bandgap of the non-metal oxide is reduced while the electron life spin improves. Oxidation of graphene, however, increases the distance between graphene sheets due to the trapping of oxygen. [18]. Moreover, the polarity of the graphene layers is improved, thus increasing water solubility. Moreover, researchers addressed this issue by applying an upgraded method to the conventional hummers' method to reduce the oxygen level, thus: reducing the insolation problem in the graphene oxide matrix.[15].. In GO, oxygen levels in graphene were respectively $31.31 \%$ to $68.69 \%$. Moreover, even after 1440 minutes of sodium borohydride $\left(\mathrm{NaBH}_{4}\right)$ as a reducing agent, the decrease method 
was not very significant, changing the percentage values for the oxygen in graphene oxide from 84.80 to 12.35 . [19].

\subsection{The Objective of this Study}

This study propose a new method for decorating/ doping graphene nanoplatelets GNP in to pure anatase phase of titanium oxide $\mathrm{TiO}_{2}$ to enhance the electron mobility in the conduction band $\mathrm{TiO}_{2}$. The strategy of the method is to ensure the correct dispersal of metal oxides and the powder form of graphene, achieving an extremely reliable weight ratio and reducing time and afford of synthesising the nanocomposite using convnsional methods.

\section{RESEARCH METHOD}

\subsection{Materials}

Titanium (IV) Oxide, Anatase Nanopowder, <25 nm Particle Size, 99.7 Trace Metals Basis. Graphene Nanopowder: AO-3: 12nm Flakes-100g, Graphene Supermarket. Ethanol 95\% Denatured, Hamburg C0312, 2-Propanol for Analysis Emsure, ACS, ISO. Acetone of Analysis Emsure, ACS, ISO. Acetic Acid, Alpha-Terpineol, Technical Grade, $90 \%$.

\subsection{Aim of Work}

This proposed method is designed to measure the powder-like doping weight ratio between $\mathrm{TiO}_{2}$ and GNP. This takes place with the help of the precious amount of adhesive materials, dilutions and synthesises the nanocomposite. A density equation is, however used for volume conversion and vice versa, as mentioned below:

$$
\mathbf{P}=\mathbf{m} / \mathbf{v}
$$

The density (P) is the material's density. In addition, mass (m) is the material divided by gravitational acceleration (gram). And meanwhile, the volume (v) is the material space (milliliters). In contrast (Table 1), the ratio of materials used in this experiment method due to the weight of $\mathrm{TiO}_{2} /$ GNP elements.

\subsection{Synthesising $\mathrm{TiO}_{2} / \mathrm{GNP}$}

As previously conducted in our work [20] detailed in Error! Reference source not found.. First beaker, the binder is produced in a weight ratio (1:10) beaker by mixing ethyl cellulose into ethanol and then magnetically stirred for two hours. In the meantime, the volume of ethanol is reserved for use on a weight / Volume ratio of (17:1) of $\left(\mathrm{TiO}_{2} / \mathrm{GNP}\right.$ powder). Second beaker, is ultrasonic with the required total amount of graphene powder with the ratio (1:13) of the already reserved ethanol for ( 2 hours), ensuring graphene sheets are dispersed and separated. There is a sequence of steps in place to ensure that the graphene powder is synthesised with the semiconductor $\left(\mathrm{TiO}_{2}\right)$ for the preparation of the dilute. Starting with Acetic Acid at DI water and $\mathrm{TiO}_{2}$ at Table 1 ratios then adding the remaining ethanol to the beaker gradually while stirring.

Next, the graphene powder is added to and stirred into the diluted $\mathrm{TiO}_{2}$. In addition, a further 30 minutes of ultrasound is needed to ensure the dispersion of graphene into metal oxide before the addition of $\alpha$-terpineol, which is then stirred for another 60 minutes. Finally, the ethylcellulose beaker is added to the $\mathrm{TiO}_{2} /$ GNP nanocomposite and repeatedly stirred for an additional eight or ten hours. Finally, after overnight stirring, the evaporation process will commence with heat exposure of 80 to $110^{\circ} \mathrm{C}$ depending on the concentration of graphene.

Table 1. The Calculation of $\mathrm{TiO}_{2} / \mathrm{GNP}$ Nanocomposite

\begin{tabular}{|c|c|c|c|c|c|}
\hline $\mathrm{TiO}_{2} / \mathrm{G}(\mathrm{gram})$ & DI water (gram) & Acetic Acid (gram) & $\alpha$-terpineol (gram) & Ethanol (gram) & Stirring Speed \\
\hline 1 & 0.8 & 0.16 & 3.3 & 17 & 500 \\
\hline 2 & 1.6 & 0.3 & 7 & 34 & 500 \\
\hline 3 & 2.5 & 0.5 & 10.7 & 51 & 1000 \\
\hline 4 & 3.3 & 0.6 & 14.5 & 68 & 1000 \\
\hline 5 & 4.1 & 0.8 & 17.7 & 85 & 1500 \\
\hline 6 & 5 & 1 & 21 & 102 & 1500 \\
\hline
\end{tabular}

a. The weight ratio of the Ethanol does not include the volume of ethanol that is already used to make the Acetic Acid paste

b. Most of the chemical materials calculated in (gram) to ensure presence measurement 


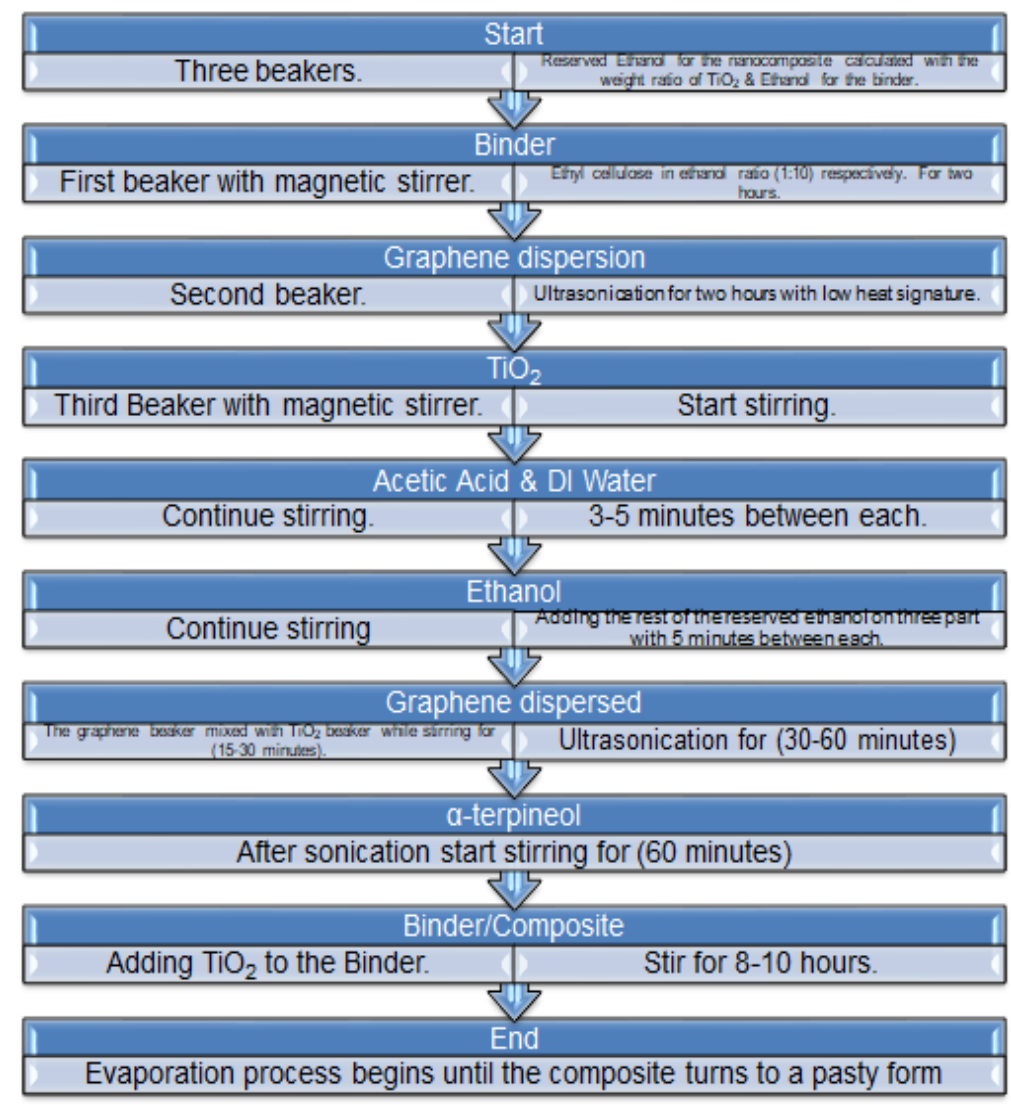

Figure 1. The proposed method of synthesising the nanocomposite of GNP and $\mathrm{TiO}_{2}$

\subsection{Thin Film}

The $2.5 \times 2 \mathrm{~cm}$ substrates are rinsed with acetone, isopropanol, and ethanol and sonicated for 15 minutes with each solvent, respectively. Then they are dried on a heat plate. A "Dr Blade" method is used to deposit the paste as a thin film on the substrates. These are baked in the furnace for 30 minutes at $450^{\circ} \mathrm{C}$ in the air to activate and crystallise the titanium.

\subsection{Instruments}

This analyses the $\mathrm{TiO}_{2}$ / GNP doping and carbon and oxygen levels in the thin film, in order to deter increased mobility of electrons. Also, different weights of the graphene-titanium nanocomposites will be checked with the same percentage ratio. Raman spectroscopy is used to define the resulting thin film microstructure's structural fingerprint. The atomic structure of nanocomposite is determined by this method. The molecular weight of carbon and titanium concerning oxygen is also observed by Energy Dispersive Spectroscopy (EDS).

\section{RESULTS AND ANALYSIS}

\subsection{Characterisation and Reliability Test}

In Figure 2. Demonstrates the evident graphic doping efficacy of the $\mathrm{TiO}_{2}$ film after rinsing synthesised composites of various levels. This begins at $0 \%$ graphene or pure $\mathrm{TiO}_{2}$ then $0.2 \%, 0.5 \%, 1 \%$, and $1,5 \%$ graphene from $\mathrm{A}$ to $\mathrm{F}$, respectively, Each stage of the concentration shows a colour difference. The colour spectrum begins from bright white with a pure $\mathrm{TiO}_{2}$ film as shown in the original film (A) and has finished in Gray-like as shown in (B, C, E, and F). The shift in colour is due to the uniform graphene concentration mixed in $\mathrm{TiO}_{2}$. In comparison, Figure 3. Shows the photocurrent measurement ( $\mathrm{I}-\mathrm{V}$ measurement) performed as a credibility test as two composites with the same graphene doping percentage as in $1 \mathrm{~g}$ and $2 \mathrm{~g}$ of the nanocomposite, Those results indicate the same voltage-current density expressed by (V) and (mA), respectively.). Therefore, the results of the last test were highly considerable since they have similarity in Fill Factor, efficiency, and Voltage-Current as the other weight nanocomposite. 


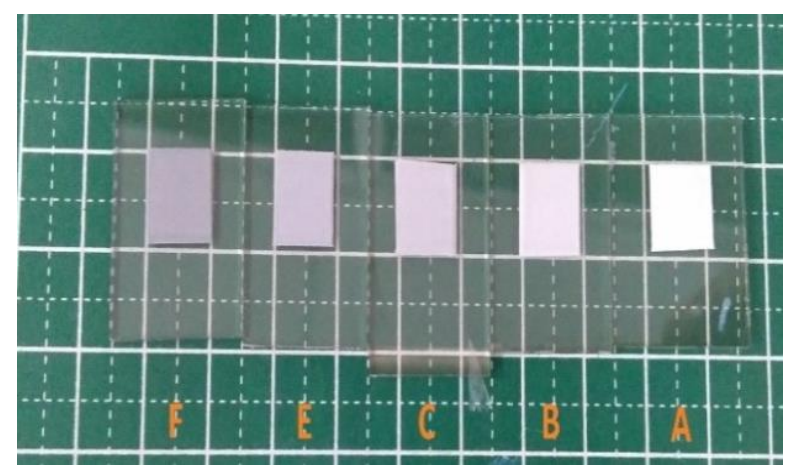

Figure 2. GNP doped into $\mathrm{TiO}_{2}$ with different consintation starting from $\mathrm{Pure} \mathrm{TiO}_{2}$ (A) to higher consintration of graphene in $(\mathrm{B}, \mathrm{C}, \mathrm{E}$, and $\mathrm{F})$, respectively

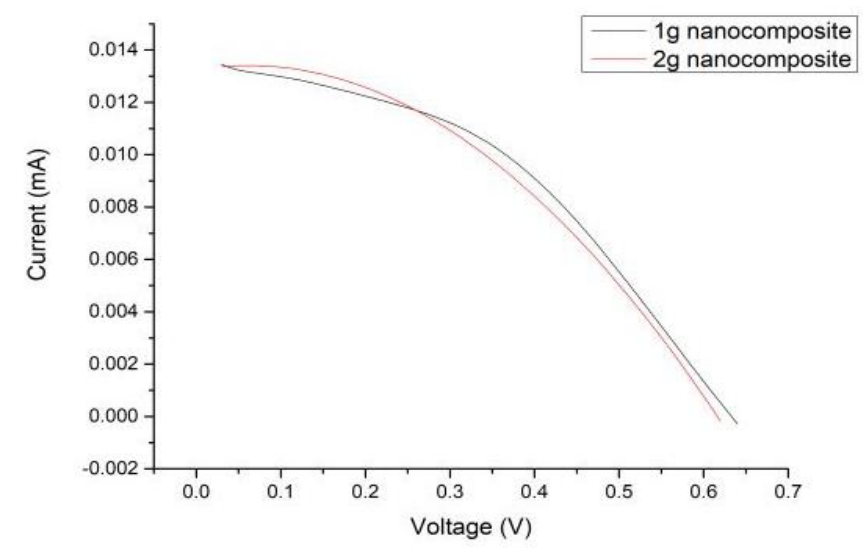

Figure 3. The measurement of two different composite with same Graphene ratio to confirm method credibility, The Blue and orange lines show nanocomposites with the same doping ratio of Graphene but differ in Titania \& Graphene weight. They have almost the same Current Voltage Curve.

\subsection{Raman Spectroscopy}

The graphs presented in Figure 4 outlines the Raman spectroscopy results on two of the postannealed $\mathrm{TiO}_{2}$ synthesised paste substrates, which were both deposited using a Dr Blade Technique. Figure 4 (a.), outlines peaks in the test sample of bare $\mathrm{TiO}_{2}$ around 150 to 500 , which is an anatase fingerprint.

Furthermore, Figure 4 (b.) shows Raman spectra of the $\mathrm{TiO}_{2} / \mathrm{GNP}$ doped solar cell. The sharp peaks reflect the film's crystallinity. The spectra show three sharp peaks at G, 2D, and D bands from $1300 \mathrm{~cm}^{-1}$ to $2750 \mathrm{~cm}^{-1}$. The $\mathrm{D}$ band indicates quasiparticles and collective exchange that can be represented by free particles like electrons and photons, which indicates high free electron mobility on the graphene side. The $\mathrm{sp}^{2}$ phonon vibrations cause peaks in the broad $\mathrm{G}$ band. The $2 \mathrm{D}$ band represents the fingerprint for Graphene as a nanocomposite with the $\mathrm{G}$ band confirming a multi-layered graphene flex [21].

\subsection{OriginPro}

In Figure 4 (b). The 2D peaks, it demonstrates the formation of nearly a single-layer of graphene represented by $2678 \mathrm{~cm}^{-1}$ and above $10 \mathrm{~cm}^{-1}$ or multi-layered graphene represented by 2697 and above $20 \mathrm{~cm}^{-1}$ [22]. Finally, to determine the subtle presence of graphene, an analysing program called OriginPro is utilised, which integrates the area under the intensity peaks. By comparing the intensity ratio of 2D/G peak in Raman Spectra derives a (9.53 ratio) of single-layered graphene sheets. However, the broadening shape of the $2 \mathrm{D}$ band is evident because of the Bernal stacking of layers, which is an ABA stack as shown in Figure 5. 


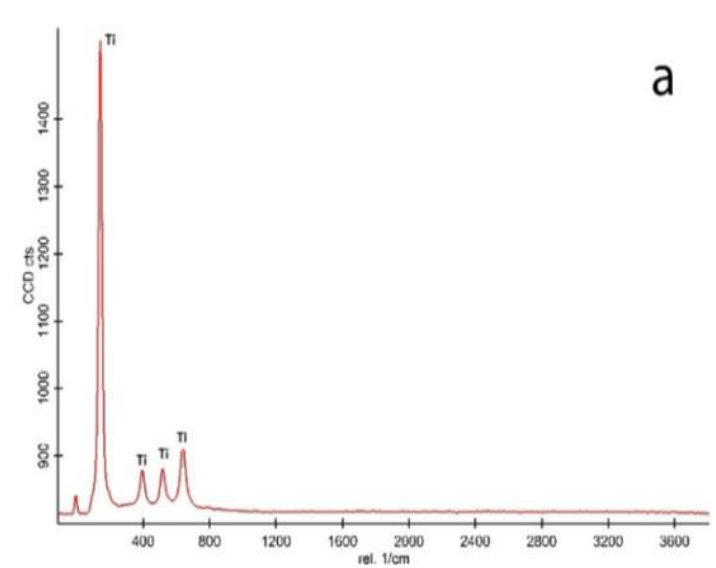

(a) Raman Spectroscopy for a bare $\mathrm{TiO}_{2}$ thin film the peaks indicate anatase phase of crystallization

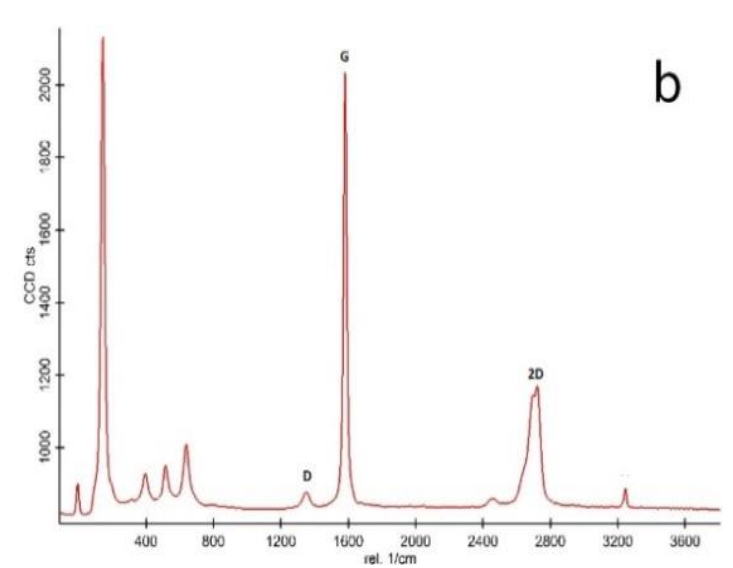

(b) Another thin film with a composite of $\mathrm{TiO}_{2} /$ GNP indicated both elementsfingerprint with a good trace of Graphene in (2D) band

Figure 4. Raman spectroscopy in respect to bare titanium oxide thin film and titanium oxide/ graphene nanocomposite

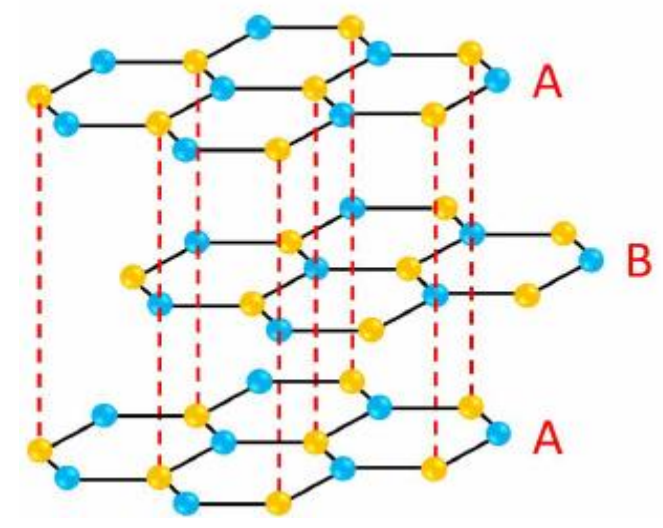

Figure 5. The ABA stacking of the graphitic layer in the thin film

\subsection{Energy Dispersive Spectroscopy (EDS)}

EDS measurements are performed on a $5 \mu \mathrm{m} 2$ area, and the results are shown in Error! Reference source not found. A thin film of a nanocomposite of $\mathrm{TiO}_{2}$ and Graphene sheets has been tested, several peaks associated with ( $\mathrm{Ti}, \mathrm{C}, \mathrm{O}$ ) are verified. Furthermore, in Error! Reference source not found. (a.), by the recognised peaks of current on the thin film, derives the weight ratio and the atomic level of the oxygen, which is lower than that of the study conducted that used Graphene oxide (GO) as a conductivity enhancer. As shown in Error! Reference source not found. (b.), this cell allows considerably more exciting free electrons to exit the thin film. [23]. Besides, as shown Table 2 gives a comparison of the results from this investigation related to other studies that use graphene oxide as a dopant. The unusual atomic level of oxygen shows that almost half of the entire circuit comprised of oxygen and confirmed a small level of carbon weight by ratio and at the atomic level. Another study involved in the table explains the results for $\mathrm{TiO}_{2} / \mathrm{Graphene}$ nanohybrids handled by nitrogen [24]. Although that study superseded in decreasing the Oxygen level, the Titanium level dramatically decreased to $7.40 \%$. Plus, that high chemical method employed with higher firing temperatures $\left(540{ }^{\circ} \mathrm{C}-700{ }^{\circ} \mathrm{C}\right)$ Another a study of CQD $[25,26]$ which applied a $\mathrm{TiO}_{2}$ photoanode to a DSSCs indicated a higher Carbon weight percentage, which is $2.94 \%$, but still lower than this study, and the Oxygen level is within a comparable normal range of $36.26 \%$, compared to $32.88 \%$ in this study. 


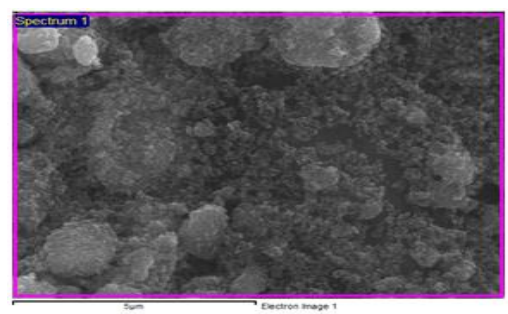

Figure 6. $\left(5 \mu \mathrm{m}^{2}\right)$ as part of the sample of study that include $\left(\mathrm{TiO}_{2} / \mathrm{G}\right)$ measured by EDS

Table 2. EDS Weight \& Atomic Percentage Level

\begin{tabular}{cccccc}
\hline Element & Weight $\%$ & Atomic\% & Weight\% [20] & Atomic\% [20] & Weight\%[21] \\
\hline OXYGEN & $32.88^{*}$ & $40.95^{*}$ & 34.97 & 53.65 & 36.26 \\
CARBON & $25.00^{*}$ & $41.48^{*}$ & 00.92 & 01.88 & 2.94 \\
TITANIA & $41.86^{*}$ & $17.42^{*}$ & 31.96 & 16.38 & 60.80 \\
SILICON & -NA & NA & 32.14 & 28.08 & NA \\
\hline
\end{tabular}

a) The previous study of CQD did not provide the Atomic\% of the EDS measurement.

b) The previous study of Nitrogen-Doped TiO2/Graphene Nanohybrids did not provide the weight percentage of the EDS measurement.

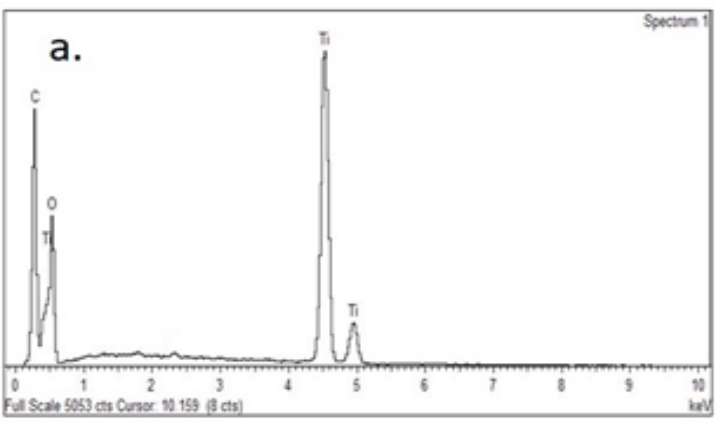

(a) measurement of our sample we can clearly see a higher peak for (Ti) and (C) compare to (O).

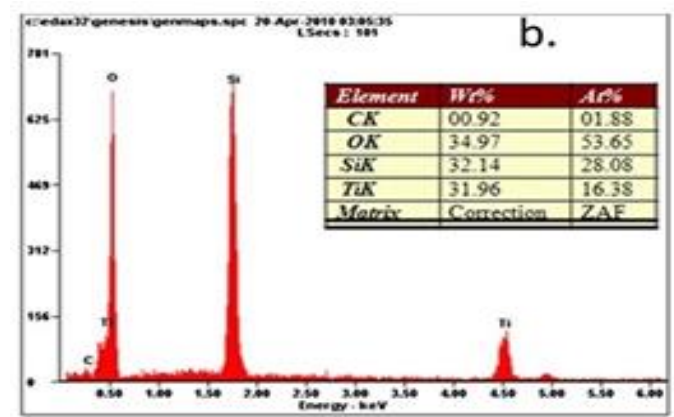

(b) a previous study for GO with lower carbon concentration compare to $(\mathrm{O})$.

Figure 7. Energy Dispersive Spectroscopy (EDS) in respect to our nanocomposite structure and a previous study in that regard [20]

\section{CONCLUSION}

In summary, NanocompositeTiO2/GNP efficiency in this research enhanced. The synthesisd TiO2 / GNP shows a significant shade of colour difference with different GNP ratios. In contrast, in colour difference with higher graphene concentrations, the various weight ratio between Titania and Graphene can be seen, indicating a consistent dispersion of the graphene particles. The I-V characterisation demonstrated credibility, as when the performance of multiple composites with the same graphene weight ratio is similar in photocurrent density characterisation. The results of Raman spectroscopy showed a 2D band for both single layer and multi-layer graphene to confirm the existence and performance of graphene within a photoanode. The spectroscopy also illustrates phonons in the electronic band structure that relate to high particles dispersal in the graphics layer.

Furthermore, The information assessment using the OriginPro software shows an expanding 2D band shape attributed to the graph layer stacks. The EDS (Energy Dispersive Spectroscopy) technique shows greater atomic mobility for both titanium and graphene, corresponding to a less oxygen-containing presence in a thin film. Since oxygen traps or redirects the electron, the mobility of the electron between the sheets is influenced by oxygen. The method used for producing devices also makes the creation of highly-functional composites time and effort cost-effective. The nanostructure also achieves an obvious decrease in oxygen, resulting in a better atomic level for graphene, which allows an improvement in photoanode layer electrons mobility. 


\section{ACKNOWLEDGEMENTS}

The authors acknowledge university Putra Malaysia (UPM) for supporting this research work under supervision and fund by Putra IPM grant (9493900) of Engineering Faculty, FRGS Grant (5540076) and Kementerian Pelajaran Malaysia (KPM) and Institute of Advanced Technology (ITMA) in which this work was possible.

\section{REFERENCES}

[1] Smalley, R. E. (2003, May). "Top ten problems of humanity for next 50 years". In Energy \& NanoTechnology Conference. Rice University

[2] B. O'Regan and M. Grätzel, "A low-cost, high-efficiency solar cell based on dye-sensitized colloidal TiO2 films," Nature, vol. 353, no. 6346, pp. 737-740, Oct. 1991.

[3] A. Hagfeldt, G. Boschloo, L. Sun, L. Kloo, and H. Pettersson, "Dye-Sensitized Solar Cells," Chem. Rev., vol. 110, no. 11, pp. 6595-6663, Nov. 2010.

[4] B. Roose, S. Pathak, and U. Steiner, "Doping of TiO2 for sensitized solar cells," Chem. Soc. Rev., vol. 44, no. 22, pp. 8326-8349, Nov. 2015.

[5] M. Ye et al., "Recent advances in dye-sensitized solar cells: from photoanodes, sensitizers and electrolytes to counter electrodes," Mater. Today, vol. 18, no. 3, pp. 155-162, Apr. 2015.

[6] A. Hegazy, N. Kinadjian, B. Sadeghimakki, S. Sivoththaman, N. K. Allam, and E. Prouzet, "TiO2 nanoparticles optimized for photoanodes tested in large area Dye-sensitized solar cells (DSSC)," Sol. Energy Mater. Sol. Cells, vol. 153, pp. 108-116, Aug. 2016.

[7] S. Malato, P. Fernández-Ibáñez, M. I. Maldonado, J. Blanco, and W. Gernjak, "Decontamination and disinfection of water by solar photocatalysis: Recent overview and trends," Catal. Today, vol. 147, no. 1, pp. 1-59, Sep. 2009.

[8] S. Shalini, R. Balasundaraprabhu, T. S. Kumar, N. Prabavathy, S. Senthilarasu, and S. Prasanna, "Status and outlook of sensitizers/dyes used in dye sensitized solar cells (DSSC): a review," Int. J. Energy Res., vol. 40, no. 10, pp. 1303-1320, 2016.

[9] Y. Li, H. Wang, Q. Feng, G. Zhou, and Z.-S. Wang, "Gold nanoparticles inlaid TiO2 photoanodes: a superior candidate for high-efficiency dye-sensitized solar cells," Energy Environ. Sci., vol. 6, no. 7, pp. 2156-2165, Jun. 2013.

[10] H. Elbohy et al., "Incorporation of plasmonic Au nanostars into photoanodes for high efficiency dye-sensitized solar cells," J. Mater. Chem. A, vol. 4, no. 2, pp. 545-551, Dec. 2015.

[11] K. Guo et al., "Preparation and enhanced properties of dye-sensitized solar cells by surface plasmon resonance of Ag nanoparticles in nanocomposite photoanode," J. Power Sources, vol. 230, pp. 155-160, May 2013.

[12] K. S. Novoselov et al., "Electric Field Effect in Atomically Thin Carbon Films," Science, vol. 306, no. 5696, pp. 666-669, Oct. 2004.

[13] Q. Zhen et al., "Honeycomb-like TiO2@GO nanocomposites for the photodegradation of oxytetracycline," Mater. Lett., vol. 228, pp. 318-321, Oct. 2018.

[14] P. Wang, F. He, J. Wang, H. Yu, and L. Zhao, "Graphene oxide nanosheets as an effective template for the synthesis of porous TiO2 film in dye-sensitized solar cells," Appl. Surf. Sci., vol. 358, no. Part A, pp. 175-180, Dec. 2015.

[15] Y.-C. Wang and C.-P. Cho, "Application of TiO2-graphene nanocomposites to photoanode of dye-sensitized solar cell,” J. Photochem. Photobiol. Chem., vol. 332, no. Supplement C, pp. 1-9, Jan. 2017.

[16] D. S. U. Peiris, P. Ekanayake, and M. I. Petra, "Stacked rGO-TiO 2 photoanode via electrophoretic deposition for highly efficient dye-sensitized solar cells," Org. Electron., vol. 59, pp. 399-405, Aug. 2018.

[17] S. Z. Siddick, C. W. Lai, and J. C. Juan, "An investigation of the dye-sensitized solar cell performance using graphene-titania (TrGO) photoanode with conventional dye and natural green chlorophyll dye," Mater. Sci. Semicond. Process., vol. 74, pp. 267-276, Feb. 2018.

[18] H. Saleem and A. Habib, "Study of band gap reduction of TiO2 thin films with variation in GO contents and use of TiO2/Graphene composite in hybrid solar cell," J. Alloys Compd., vol. 679, no. Supplement C, pp. 177-183, Sep. 2016.

[19] L. G. Guex et al., "Experimental review: chemical reduction of graphene oxide (GO) to reduced graphene oxide (rGO) by aqueous chemistry," Nanoscale, vol. 9, no. 27, pp. 9562-9571, Jul. 2017.

[20] H. A. AlSultan, M. A. Mustafa, S. Shafie, W. Z. W. Hasan, and A. Khalifa, "Graphene Doping Technique in TIO2 for Dye-Sensitized Solar Cells Photo-Anode," in 2018 IEEE 5th International Conference on Smart Instrumentation, Measurement and Application (ICSIMA), 2018, pp. 1-5.

[21] S. N. F. Zuikafly, A. Khalifa, F. Ahmad, S. Shafie, and S. Harun, "Conductive graphene as passive saturable absorber with high instantaneous peak power and pulse energy in Q-switched regime," Results Phys., vol. 9, pp. 371-375, Jun. 2018.

[22] M. R. Subramaniam, D. Kumaresan, S. Jothi, J. D. McGettrick, and T. M. Watson, "Reduced graphene oxide wrapped hierarchical TiO 2 nanorod composites for improved charge collection efficiency and carrier lifetime in dye sensitized solar cells," Appl. Surf. Sci., vol. 428, pp. 439-447, Jan. 2018.

[23] D.-H. Yoo et al., "Enhanced photocatalytic activity of graphene oxide decorated on TiO2 films under UV and visible irradiation," Curr. Appl. Phys., vol. 11, no. 3, pp. 805-808, May 2011. 
[24] R. Wang et al., "Preparation of Nitrogen-Doped TiO2/Graphene Nanohybrids and Application as Counter Electrode for Dye-Sensitized Solar Cells,” ACS Appl. Mater. Interfaces, vol. 6, no. 3, pp. 2118-2124, Feb. 2014.

[25] Z. Salam, E. Vijayakumar, A. Subramania, N. Sivasankar, and S. Mallick, "Graphene quantum dots decorated electrospun $\mathrm{TiO} 2$ nanofibers as an effective photoanode for dye sensitized solar cells," Sol. Energy Mater. Sol. Cells, vol. 143, pp. 250-259, Dec. 2015.

[26] Morsin, M., Isaak, S., Morsin, M., \& Yusof, Y., "Characterization of Defect Induced Multilayer Graphene," International Journal of Electrical and Computer Engineering, 7(3), 1452

\section{BIOGRAPHIES OF AUTHORS}

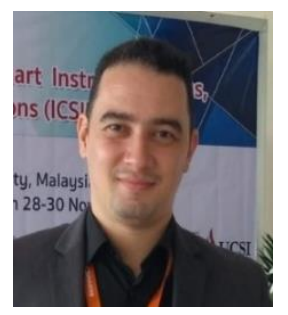

Hussein Abdulsalam Ali AlSultan recevied bachelor of engineering (Department of Computer technique engineering) from Al-Rafidain University College, Iraq in 2010. Currently a master student in engineering (Computer and Embedded Systems Engineering) at Universiti Putra Malaysia. The area of interest in renewable energy, Dye-Sensitized Solar Cells (DSSC), Organic Solar Cells. And Graphene based technology

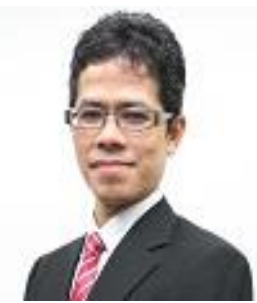

Mohd Amrallah Mustafa received the Bachelor of Engineering (Electrical and Electronics) from Universiti Putra Malaysia, Malaysia in 2000. He received the Master of Engineering (Control and Automation) also from Universiti Putra Malaysia, Malaysia and $\mathrm{PhD}$ (Eng.) in Nano vision from Shizuoka University, Japan in 2007 and 2013, respectively. He is a Senior Lecturer in Universiti Putra Malaysia. Dr. Mohd Amrallah is working in Solar Cell, CMOS Image Sensors, Analog IC design and robotics. His current projects include Charging Pad for Unmanned Aerial Vehicle and High Efficiency Dye Sensitized Solar Cell. He was the Excomm of IEEE Circuits and Systems Malaysia Chapter and vice secretary of IEEE EDS Malaysia Chapter. He actively involves in IEEE CAS and EDS Malaysia Chapters activities.

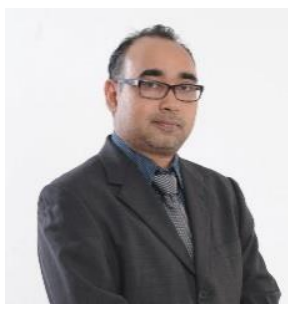

Suhaidi Shafie: received the Bachelor of Engineering (Electrical and Electronics) from University of the Ryukyus, Japan in 2000. From 2000 to 2002, he was with ALPS Electric (M) Sdn. Bhd. He received the Master of Engineering (Electrical and Electronics) from Tokyo University of Agriculture and Technology, and the Doctor of Engineering (Nanovision) from Shizuoka University in 2005 and 2008, respectively. He is an Associate Professor in Universiti Putra Malaysia and the Head of Functional Devices Laboratory. Dr. Suhaidi is working in Mix Signal IC Design and Solar Energy research. His current projects include Ultra Low Power SAR ADC and High Efficiency Dye Sensitized Solar Cell. He is was the chapter chair of IEEE Circuits and Systems Malaysia Chapter and actively involves in IEEE CAS and IMS Malaysia Chapters activities.

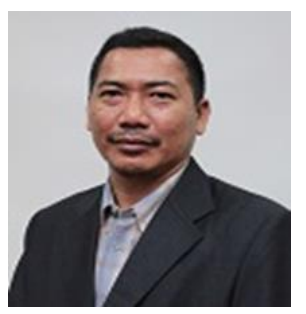

Wan Zuha Wan Hasam received the degree in Electrical and Electronic Engineering from Universiti Putra Malaysia in 1997. He received the Ph.D. degree in Microelectronic Engineering from the Universiti Kebangsaan Malaysia in 2010. Currently, he is a senior lecturer at Department of Electrical and Electronic Engineering, Universiti Putra Malaysia. His research interests include Memory Testing, MEMS Sensor and Robotic and Automation

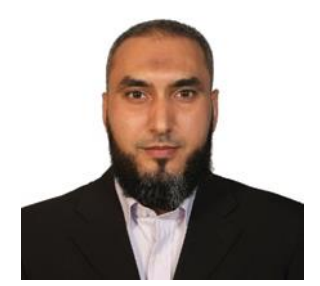

Ali Khalifa has an M.Sc. in Electronic Systems Design Engineering Sciences from USM University - Malaysia (2006). He is a senior Assistant Lecturer in College of Industrial Technology in Libya. Mr. Khalifa is currently a Ph.D. student in Electronic Engineering department at Universiti Putra Malaysia. His interest areas of research include Dye-Sensitized Solar Cells (DSSC), Graphene and Carbon-based conductive films and their deposition techniques as well as nanomaterials characterizations. 